\title{
50 anos de experiência na Amazônia: Entrevista com Alfredo Wagner Berno de Almeida
}

50 years of experience in the Amazon: Interview with Alfredo Wagner Berno de Almeida

\section{Renata Barbosa Lacerda e Igor Rolemberg}

\section{(2) OpenEdition}

\section{Journals}

\section{Edição electrónica}

URL: https://journals.openedition.org/aa/9314

DOI: 10.4000/aa.9314

ISSN: 2357-738X

\section{Editora}

Programa de Pós-Graduação em Antropologia Social (UnB)

Edição impressa

Paginação: 108-130

ISSN: 0102-4302

\section{Refêrencia eletrónica}

Renata Barbosa Lacerda e Igor Rolemberg, «50 anos de experiência na Amazônia: Entrevista com Alfredo Wagner Berno de Almeida», Anuário Antropológico [Online], v.47 n.1 | 2022, posto online no dia 31 janeiro 2021, consultado o 24 julho 2022. URL: http://journals.openedition.org/aa/9314 ; DOI: https://doi.org/10.4000/aa.9314

\section{(c) $($ ) $\odot \odot$}

Creative Commons - Atribuição-NãoComercial-SemDerivações 4.0 Internacional - CC BY-NC-ND 4.0 https://creativecommons.org/licenses/by-nc-nd/4.0/ 


\section{Anuário Antropológico}

v.47 n.1 | 2022

2022/v.47 n.1

\section{0 anos de experiência na Amazônia: Entrevista com Alfredo Wagner Berno de Almeida}

50 years of experience in the Amazon: Interview with Alfredo Wagner Berno de Almeida

\section{Paula Lacerda e Igor Rolemberg}

\section{OpenEdition \\ Journals}

\section{Edição electrônica}

URL: http://journals.openedition.org/aa/9314

DOI: $10.4000 /$ aa.9314

ISSN: 2357-738X

\section{Editora}

Programa de Pós-Graduação em Antropologia Social (UnB)

\section{Referência eletrônica}

Renata Lacerda e Igor Rolemberg, «50 anos de experiência na Amazônia: Entrevista com Alfredo Wagner Berno de Almeida», Anuário Antropológico [Online], v.47 n.1 | 2022. URL: http://journals. openedition.org/aa/9314 ; DOl: https://doi.org/10.4000/aa.9314

\section{(c) (i) (우요}

Anuário Antropológico is licensed under a Creative Commons. Atribuição-SemDerivações-SemDerivados CC BY-NC-ND 


\title{
entrevista
}

\author{
. $47 \cdot n^{0} 1 \cdot$ janeiro-abril - 2022.1
}




\title{
50 anos de experiência na Amazônia: Entrevista com Alfredo Wagner Berno de Almeida
}

\author{
50 years of experience in the Amazon: Interview with Alfredo Wagner Berno de Almeida
}

DOI: https://doi.org/10.4000/aa.9314

\begin{abstract}
Renata Barbosa Lacerda
Universidade Federal do Rio de Janeiro, Museu Nacional - Brasil

Doutoranda no Programa de Pós-Graduação em Antropologia Social, Museu Nacional, Universidade Federal do Rio de Janeiro (PPGAS/MN/UFRJ), Rio de Janeiro, RJ, Brasil. Pesquisadora do Núcleo de Antropologia da Política (NuAP) e do Núcleo de Estudos sobre Amazônia Contemporânea (NUAMA/UERJ).
\end{abstract}

\section{Igor Rolemberg}

École des Hautes Études en Sciences Sociales, Centre Maurice Halbwachs - França

Universidade Federal do Rio de Janeiro, Museu Nacional - Brasil

Doutorando em Ciências Sociais pela École des Hautes Études en Sciences Sociales (EHESS), em cotutela de tese com o Programa de Pós-Graduação em Antropologia Social do Museu Nacional (UFRJ). Pesquisador do Núcleo de Antropologia da Política (NuAP) e do Núcleo de Estudos sobre Amazônia Contemporânea (NUAMA/Uerj).

Entrevista com Alfredo Wagner Berno de Almeida, antropólogo, membro da coordenação do Projeto Nova Cartografia Social da Amazônia (PNCSA) que trabalha no Amazonas. A entrevista foi realizada de modo remoto por Renata Lacerda e Igor Rolemberg em 10 de maio de 2021. 0 objetivo foi mapear continuidades e mudanças nas relações entre, de um lado, mobilizações sociais por reforma agrária e territorialidades específicas e, de outro, as agroestratégias e intervenções estatais na Amazônia. O pesquisador refletiu sobre os marcos teóricos e metodológicos que fundamentaram a análise desses processos, sobretudo no campo da antropologia.

Entrevista; Alfredo Wagner Berno de Almeida; Amazônia; conflitos sociais; antropologia.
Interview with Alfredo Wagner Berno de Almeida, anthropologist and coordinator of the New Social Cartography of the Amazon Project (PNCSA) who works in the state of Amazonas. The interview was conducted remotely by Renata Lacerda and Igor Rolemberg on May 10, 2021. The objective was to map continuities and changes regarding the relations between, on the one hand, social mobilizations for agrarian reform and specific territorialities and, on the other hand, the agribusiness strategies and state interventions in the Amazon. The researcher reflected on the theoretical and methodological frameworks that underpinned the analysis of these processes, especially in the field of anthropology.

Interview; Alfredo Wagner Berno de Almeida; Amazon; social conflicts; anthropology. 


\section{Introdução}

Alfredo Wagner reside em Manaus (AM). Possui mestrado (1978) e doutorado (1993) em Antropologia Social pela Universidade Federal do Rio de Janeiro (UFRJ). No mestrado, sob orientação de Moacir Palmeira, realizou trabalho de campo no Maranhão e sua dissertação tratou da obra de Jorge Amado. No doutorado, sob orientação de Luiz de Castro Faria, trabalhou com história da ciência e analisou conflitos agrários envolvendo comunidades rurais, mediadores religiosos e Estado na Amazônia desde os anos 1960-70.

Atualmente, é professor da Universidade Federal do Amazonas (UFAM), Universidade Estadual do Maranhão (UEMA) e Universidade do Estado do Amazonas (UEA). Integra a coordenação do Projeto Nova Cartografia Social da Amazônia (PNCSA) e é conselheiro regional e coordenador do GT de Direitos Humanos da Sociedade Brasileira para o Progresso da Ciência (SBPC).

Em outras entrevistas (Aragão e Oliveira, 2019 [2012]; Dias 2009; Lima, Ramos, e Silva, 2013), Alfredo Wagner abordou temas como a nova cartografia social, a emergência de identidades coletivas objetivadas em movimentos sociais, bem como sua trajetória profissional na antropologia e em instituições públicas.

Frente ao atual contexto de desinstitucionalização de políticas e legislações agrária, fundiária e ambiental em nome dos agronegócios, julgamos pertinente que refletisse sobre continuidades e mudanças nas relações entre, de um lado, mobilizações sociais por reforma agrária e territorialidades específicas e, de outro, as agroestratégias e intervenções estatais na Amazônia.

Com base em cerca de cinquenta anos de atividades de pesquisa na região e em diálogo com experimentações e trabalhos de campo em variadas situações coloniais nas Américas do Sul e Central e também no continente africano (Quênia), o antropólogo sublinhou questões políticas, teóricas e metodológicas que fundamentaram e desafiaram trabalhos e interpretações na e sobre a Amazônia.

A entrevista foi realizada em maio de 2021, segundo ano de pandemia da covid-19, pela plataforma de videoconferências Zoom. Igor estava em Aracaju, Renata no Rio de Janeiro e Alfredo Wagner em Manaus. A transcrição do áudio foi realizada por Vanessa Henriques, a quem agradecemos pelo trabalho. Agradecemos ainda a Paula Lacerda e a Carolina Parreiras, pelo auxílio na execução da entrevista pelo Zoom. A primeira edição foi feita por Igor e Renata, e revisada por Alfredo Wagner.

Renata Lacerda: Durante seu mestrado no Programa de Pós-Graduação em Antropologia Social do Museu Nacional (UFRJ), o senhor realizou uma extensa pesquisa bibliográfica e de campo no Maranhão e no Pará sobre trabalho assalariado e campesinato nas chamadas terras livres da Amazônia. A tese de doutorado (Almeida 1993, 2014) condensa vinte anos de trabalho de campo na Amazônia, iniciado em 1972, a partir de conflitos envolvendo comunidades rurais, mediadores religiosos e Estado. Como o senhor vê hoje seu percurso intelectual na antropologia e sua relação com a região amazônica, onde reside e continua trabalhando 
em diversas frentes institucionais, especialmente no Amazonas e no Maranhão?

Alfredo Wagner Berno de Almeida: Muito obrigado pelo convite. Peço-lhes licença para fazer um preâmbulo ou melhor um prólogo, para o conjunto de perguntas. Elas me levam à necessidade de esclarecer o que por vezes me parece difícil de distinguir: considerações autobiográficas e interpretação reflexiva. Quer dizer, uma coisa é a informação autobiográfica que faculto a vocês. Outra é a interpretação reflexiva sobre a minha trajetória profissional. Numa citação epigráfica, em "Esboço de Autoanálise”, Bourdieu (2005) assinala tal distinção. Ao contrário da descrição com características autobiográficas, a análise reflexiva consiste num trabalho conceitual. Esse trabalho implica um retorno interpretativo sobre as abordagens teóricas adotadas e sobre as nossas próprias práticas de pesquisa. Essas práticas são orientadas pela lógica da pesquisa, concomitante à delimitação de seu objeto. Quer dizer, a maneira de pensar o objeto de pesquisa é parte do objeto. A abrangência desse objeto de reflexão é muito vasta, implicando uma leitura crítica e um confronto com outras posturas teóricas.

[Numa conversa prévia], vocês me honraram muito chamando o que eu produzi de "obra”. Não creio que seja "obra”, sinceramente. São trabalhos esparsos, reflexões coladas com situações às vezes localizadas. Elas não chegam a compor, no sentido de [Georges] Canguilhem (2000 [1977]), uma "obra". Não me sinto autor de "obra". Muito pelo contrário: me sinto autor de breves e circunstanciais intervenções no domínio da produção científica, algo esparsas e ligadas à própria dispersão dos trabalhos de pesquisa que executo.

Nesse sentido, as abordagens teóricas adotadas nas práticas que desenvolvi são atreladas à lógica de pesquisa, influem no seu objeto e também objetivam uma análise crítica procedendo à gênese social de conceitos e à elaboração de "metáforas antagonistas". Há metáforas em demasia nas descrições usuais e aprendi a lutar contra elas. Os que me orientaram, os professores Moacir Palmeira e [Luiz de] Castro Faria, me levaram a uma reflexão crítica no que concerne às autoevidências, fetiches verbais, analogias e metáforas, me impulsionando a produzir aquilo que [Jacques] Derrida (1991 [1972]) fala sobre [Henri] Bergson, isto é, "metáforas antagonistas", que destroem o sentido da linguagem figurada ou das próprias metáforas. Toda essa discussão sobre "questões agrárias", trabalho assalariado no campo e modalidades de uso dos recursos, está marcada por uma retórica eivada de lugares comuns que incorporam sucessivas metáforas. Esta é uma dificuldade, um obstáculo à compreensão sociológica, que exige um esforço crítico permanente sobre modelos, instrumentos de formação de categorias, critérios de classificações e dos próprios esquemas interpretativos.

Vocês mantiveram nas indagações que me foram remetidas uma certa sequência histórica, que pode ser vista como uma cronologização, com todo respeito, ingênua e acrítica, digamos assim. Romper com essa noção banalizada de "linha do tempo" faz-se imprescindível. [Michel] Foucault (2010 [1976]) procede a tal discernimento na elaboração do conceito de resistência, ao afirmar que não é passível de ser cronologizada. Porque para ele o tempo não seria linear, nem sujeito a uma anterioridade lógica. Se interpretarmos deste modo as trajetórias 
intelectuais, poderemos destacar variações, porque vão se modificando pelo conjunto de relações sociais que vão estabelecendo em diferentes tempos, quase a descrever um zig-zag teórico. Por isso, no que me diz respeito, não creio que se possa dizer “ah! é uma obra”. Que nada! Há várias inconsistências e incongruências, distorções conceituais e dificuldades teóricas nos trabalhos que executo, o tempo todo marcados não necessariamente por acúmulos, mas por relações de pesquisa dinâmicas, muito tensas e difíceis. Capital intelectual não significa acúmulo contínuo de conhecimentos, mas relações sociais dinâmicas e, por vezes, controversas.

\section{Da sociologia à antropologia}

Imaginem que a minha primeira aproximação profissional não foi com a antropologia. Vim da sociologia e da ciência política para a antropologia. Aliás, no Museu Nacional, quando cursei o mestrado, muitos haviam feito esse percurso. Muitos com quem convivi então, direta ou indiretamente, alguns mais velhos, outros mais novos, conheci-os na PUC [Pontifícia Universidade Católica], na Escola de Sociologia e Política. Então o que me atraía era o trabalho em sociologia. Só fui para antropologia porque em sociologia não se estava fazendo o trabalho de pesquisa que imaginava. Fiz exames para admissão no PPGAS do Museu Nacional e fui aprovado, três meses após ter saído da prisão. Fui preso no final de 1970. Fiquei preso até 1972. Em março de 1972 fui absolvido pela Justiça Militar. Cumpri arbitrariamente pena a despeito da absolvição. Bom, era uma ditadura. Ao ser solto, voltei à PUC e frequentei um curso ministrado pela professora Lygia Sigaud, que foi fundamental para consolidar meus interesses de pesquisa, bem como a preferência pela antropologia. Li Malinowski, Mauss, Lévi-Strauss, Pritchard e Berreman, dentre outros.

Meus colegas foram de certa maneira meus professores nesta passagem entre domínios de conhecimento. Aqueles com quem havia convivido na universidade tornaram-se meus professores, quando retornei à PUC: Terri Valle de Aquino, João Pacheco [de Oliveira], José Sérgio Leite Lopes e Afrânio Garcia, dentre tantos outros, foram de certa maneira meus mestres ditosos. Certamente que o contato com abordagens teóricas mais próprias da antropologia dificultou um pouco a minha redefinição, obrigando-me a estudar muito. Nunca havia pensado em fazer pesquisas referentes a campesinato, povos indígenas ou "pensamento social brasileiro". Jamais pensara em estudar trajetórias intelectuais como as de Euclides da Cunha e Jorge Amado (Almeida 1977, 1979). Nunca pensei em fazer pesquisas concernentes à história da ciência; sobre museus e coleções.

Os anos de 1972/73 foram relevantes para mim porque o conceito de camponês estava sendo bastante trabalhado, obrigando-me a desdobrar em leituras e fichamentos. O trabalho conceitual executado principalmente pelos professores Moacir Palmeira e Otávio Velho, no curso "Sociedades Camponesas", abria uma discussão permanente sobre questão agrária. Lemos autores do leste europeu: [Teodor] Shanin, [Alexander] Chayanov, [Karl] Kautsky, [Boguslaw] Galeski, [Jerzy] 
Tepicht; da Ásia, Hamza Alavi, e da América do Sul, Eduardo Archetti, que refletiram sobre a economia camponesa e o Estado. Também lemos os norte-americanos, que produziram etnografias na América Central: [Robert] Redfield, [Eric] Wolf, Sidney Mintz, [George] Foster e Sol Tax. Durante três anos percorri essa literatura (Almeida 2013a).

\section{Formação no trabalho de campo}

Em julho de 1972 Terri Aquino, João Pacheco e eu fomos apresentados por Lygia Sigaud a Laís Mourão e Regina Prado para realizarmos trabalho de campo, como seus assistentes. Tratava-se de pesquisa relativa à avaliação da ação missionária canadense na Baixada Maranhense, para elas produzirem suas dissertações. Fiquei sozinho num povoado de beira-campo, distante mais de $20 \mathrm{~km}$ daquele onde estavam colegas e a sede da pesquisa. Tive que me virar, digamos assim, em algo que eu não estava muito preparado. Não tinha o controle das minhas impressões, lembrando a experiência no Himalaia descrita por [Gerald] Berreman (1975).

Muitas vezes me perdia inteiramente. Meu caderno de campo é um atestado de minha incompetência em traçar um elenco sequente de atividades, de como ia me confundindo no dia a dia. Por exemplo, não percebi de imediato que estava dentro de um imóvel rural, que era uma fazenda. Achei que as pessoas eram livres e de fato o eram, em certa medida, mas pagavam o aforamento e havia subordinações não aparentes. Esse foi um dos problemas iniciais de minha inserção no campo. Havia uma defasagem entre o legal e o efetivo.

A primeira situação desafiante que vivi foi procurar entender aquela unidade social, uma comunidade autodenominada "aqui é a terra dos pretos". Viver cotidianamente com eles, morar na casa de uma das famílias, jogar futebol num campo que eles montaram, ir à noite assistir as aulas na "tribuna" que eles construíram, ir com eles à pesca, aos lugares de cultivo para colher a mandioca e transportá-la para a "casa de forno" onde faziam a farinha, e entrevistá-los, não era suficiente para compreendê-los. Era um tempo de colheita, após a estação chuvosa, e vivi intensamente esta experiência formadora. Vinha de uma visão estereotipada do que poderia ser uma unidade social dessa ordem, muito marcada por um certo formalismo teórico do conceito de comunidade. Estava diante de uma unidade social autodefinida pelos seus integrantes como "comunidade" e ao mesmo tempo exigia de mim um conceito teórico de comunidade, capaz de dialogar com aquela autodefinição. Essa foi uma outra dificuldade que inicialmente enfrentei. O meu propósito inicial era fazer a dissertação sobre isso. Tive, entretanto, problemas. Não consegui. Embora eu tenha voltado, por mais de seis anos, passando semanas com eles. Mantenho relações de pesquisa até hoje com comunidades relativamente próximas, como as de Alcântara.

E lá se vão quase 50 anos dessa experiência de campo. Uma experiência da qual me beneficiei muito, sob vários aspectos, inclusive no que tange à montagem de equipe de pesquisa. Digo isto porque dividimos o honorário: Terri Aquino, João Pacheco e eu. Era um único honorário para os três. Viajamos durante dias 
de ônibus para lá, para essa região, depois de barco. Separados, porque naquele tempo não era muito conveniente viajar em grupo, ainda mais quando havia um recém-saído de prisão. Aliás, fui interrogado brevemente por policiais federais no povoado em que estava. Perseguiam contrabandistas, conforme disseram, e as famílias da comunidade foram muito veementes na minha defesa, quando começaram publicamente a me perguntar o que fazia ali. Mais tarde as autoridades solicitaram à ordem religiosa que procedesse à entrega dos materiais da pesquisa.

Nestes dias, em que a professora do povoado estava grávida, não podendo lecionar, fui convidado para dar aulas [de alfabetização] à noite. Não me sentia qualificado para tanto, mas havia tido uma breve experiência durante o curso na PUC. Muitos colegas eram exímios alfabetizadores, trabalhavam no chamado "bairro proletário", contíguo à PUC. Além de alfabetização, havia quem lecionasse matemática à noite em colégios, como o Santo Inácio, também dos jesuítas, para operários da construção civil, como o fazia Terri Aquino.

Era um tempo em que nós éramos muito incentivados a exercitar nossa liberdade, e a atração acadêmica em si tornara-se circunstancialmente menor. A condição de professor tornara-se fragilizada. Até hoje não sou propriamente professor, nem funcionário público, embora lute para reinventar o serviço público e a ação pedagógica. Mesmo sabendo dos equívocos da distinção entre ensino e pesquisa, gostaria de lembrar que as atividades que realizei e realizo emergem a partir de trabalhos de pesquisa.

Penso hoje que a relação intensa que estabeleci com agentes sociais e objetos de pesquisa no trabalho antropológico estava muito filtrada por aquelas situações contingenciais. Elas é que me impeliram ao exercício constante da autonomia. Deste modo, lendo essas perguntas de vocês, tive dificuldade de separar o que é autobiográfico do que é uma interpretação reflexiva. O que é uma leitura crítica de uma trajetória própria e o que é uma ilusão biográfica dessa mesma trajetória em que fabriquei imaginações que perduram sobre a autonomia possível no trabalho de pesquisa.

Inicialmente fui trabalhar no Maranhão. Aliás, nesse trabalho de campo, fiquei quase cinco meses e não era para ficar tanto. A previsão era de um mês. Para mim, a experimentação era um elemento central no trabalho de pesquisa. E não correspondia àquela experiência que era interpretada, no fim dos anos 1960, como empirismo. Não! As pessoas confundiam a observação empírica com recursos teóricos tomados a uma perspectiva empirista. Em decorrência, se "afastavam" de processos reais e realidades localizadas, e não era isso que estava em jogo. A nossa experimentação de pesquisa utilizava conceitos complexos nas descrições etnográficas. Trabalhava estes conceitos, fazendo variar suas possibilidades de abrangência e compreensão, como assevera Canguilhem (1990)ํㅜㄹ. Buscávamos novos recursos e instrumentos de produção de um conhecimento etnográfico. Claro que errávamos pra caramba.

Por exemplo: em 1972 fiquei sozinho no povoado. Quando eu ia observar as atividades, quando as famílias estavam no final da colheita ou abrindo terrenos para cultivo ou executando a semeadura da "roça de verão", o "sangal", eu fazia o
1 Sobre o procedimento de trabalhar o conceito, cf. Louis Pinto (2014). 
trabalho das crianças: carregava água, ajudava a transportar a comida. Me pediam para fazer isto. Quer dizer, eu não era visto como um homem, na sua expressão completa. Era visto como meio homem, colocado sempre na situação de liminaridade. Não usufruía da adultez. Não tinha um “pataxo nas mãos”, como diziam, para preparar o terreno. Por outro lado, havia situações outras. Era um período de festas, de início da estação seca, imediatamente pós-colheita. Ia muito às festas. Adorava dançar, dançava muito, me divertia, participava das cantorias, gostava disto. Às vezes a gente viajava a noite inteira para ir a uma festa, um bumba-meu-boi. Eu não teria o fôlego do Terri que gravou "um bumba-boi" de $8 \mathrm{~h}$ da noite às $7 \mathrm{~h}$ da manhã, justamente porque me colocava disponível, confundindo meus próprios afazeres. De repente estava dançando, mas não estava gravando, e me solicitavam para ajudar fulano que bebera muito ou para ajudar a carregar as caixas de som da radiola. De pronto me dispunha a fazê-lo. Tinha uma inserção aparentemente mais solta. O Terri vinha de uma disciplina da ordem jesuítica, sua inserção era mais severa, mais austera. Como a vida cotidiana comporta paradoxos em demasia e algo inexplicáveis aparentemente não era assim. A austeridade parecia, aos olhos dos agentes sociais, que estava em mim. Mas não, eu me sentia uma pessoa bastante aberta, talvez insegura. A dinâmica destas relações com a exposição de meus equívocos me levava a estudar mais. Foi extremamente formativa. O trabalho de campo exigia paciência e acuro, e me via quebrando a cabeça com os conceitos ao tentar registrar no caderno de campo triviais ocorrências da vida cotidiana.

\section{A descoberta do "comum" e das identidades específicas}

Com as leituras e discussões do curso "Sociedades Camponesas" percebi que a unidade social em que me encontrava, em 1972, estava referida a um antigo engenho que conheceu a sua derrocada com a queda do preço do açúcar. Depois que li Sidney Mintz (1985), com a noção de "brecha camponesa" na plantation, e Eric Wolf (1957), penso que avancei na compreensão daquela situação social. Passei a interpretar uma situação de campesinato que foi se formando a partir da desagregação da grande plantação e do engenho. Era isso que parecia. Realizei um censo, enumerando as unidades familiares, suas relações de parentesco e afinidade, e elaborei um mapa, na verdade um croqui, atividades elementares na prática etnográfica e das quais um aprendiz não pode escapar. Registrei os vestígios do antigo engenho: rodas de ferro, restos de moenda, chapas de cobre torcidas, o dique e o lugar físico da moagem.

Mintz e Wolf utilizaram o conceito de plantation, caracterizada por economia agrário-exportadora, monocultura, imobilização da força de trabalho, concentração de imensas extensões de terra e com uma parte industrial. Nas discussões sobre o trabalho que apresentei, Moacir, com muita ênfase, indagava: "Mas é mesmo uma plantation?". Havia controvérsias se era uma grande plantação, um engenho ou uma plantation. A situação apresentada não correspondia ao conceito de plantation, de Mintz, nem ao de hacienda, de Wolf. Nos estudos mais detidos, ao coligir os 
dados de campo, fui impelido a fazer várias aproximações e contrastes, diferenciações e correspondências, retendo elementos da interpretação de um "campesinato pós-plantation" no caso da compreensão dos denominados "foreiros".

Destaquei algumas formas de relação que me tocaram muito e que evidenciavam uma modalidade de imobilização da força de trabalho: o aforamento. Os "foreiros" efetuavam o pagamento, correspondente às "braças" de terra efetivamente usadas a cada ciclo agrícola, que eles chamavam de "foro" esta taxa por "linha" plantada. Três "linhas" perfaziam um hectare e eram medidas com cordas, por metro. $\mathrm{E}$ havia um medidor oficial de confiança dos proprietários que assim procedia. Comecei a andar com esse medidor, registrando as áreas de cultivo no croqui. Havia mais de uma centena de "roças". Comecei a entender a diferenciação econômica interna entre os "foreiros" pelo tamanho da área plantada e como se dava a relação deles com os chamados "donos".

Cheguei a pensar que iria fazer minha dissertação a partir destas observações. Acabei produzindo alguma coisa, mas não me senti autorizado a transformar meu trabalho em dissertação. Achei que estava desrespeitando aquelas pessoas que tinham me acolhido tão bem. Naquele momento pensei assim: "Caramba, eu transformar isso aqui em uma tese acadêmica? Vou fazer isso com essas pessoas?”. Foi muito difícil para mim, não consegui resolver isso na minha cabeça.

Fui apresentado a eles para efetuar uma avaliação da ação missionária e agora iria informar que procederia a uma pesquisa de interesse próprio? As críticas à ação missionária eram constantes. Havia um grave conflito dos clérigos com o sistema de casamento vigente na comunidade, não baseado na monogamia. Fui percebendo que o lugar da briga parecia estar na crítica à ação religiosa colonizadora. Parecia que uma dissertação não iria ajudá-los em nada, tive vergonha disso. Uma conversa com o chefe de família em cuja casa ficava consolidou tal intuição. Ele polemizava com os padres, mas não pensava em desapropriação do imóvel rural. Achava que como "foreiros", recolhendo um foro de baixo valor, continuariam se reproduzindo. Não interpretei isto como passividade, mesmo quando me disse que viviam assim desde seu avô, que conhecera a escravidão. Comecei a ajudar no âmbito dos direitos à organização e à terra. Contribuí para a montagem do sindicato local, na vinculação dele à federação e na instalação de uma delegacia sindical. Não era uma militância. Estava vindo de uma experiência política que me fez sair criticamente da pretensão de centralidade na ação político-organizativa. A pesquisa antropológica objetivada em laudos, perícias e pareceres não se confunde com a ação mediadora e com as disciplinas militantes próprias de associações voluntárias da sociedade civil. Por não haver consenso nisto, certamente essa é uma discussão a ser feita continuamente.

Em 1974 tive um financiamento da Fundação Ford para estudar as modalidades de "trabalho assalariado" nos projetos agropecuários em implantação no Pará. Viajei pela rodovia "Pedro Teixeira", fiquei dois meses pelas pensões de beira de estradas e da periferia de Belém, que me eram indicadas como pontos de recrutamento de trabalhadores rurais do Maranhão que, uma vez no Pará com destino ao Projeto Jari e outros empreendimentos agropecuários, recebiam a designação de
2 "Foro" é um instituto jurídico que, desde a Colônia, designa o pagamento ou contraprestação que deve ser efetuada por um particular, a quem é concedido o uso e posse de uma parcela de terra pública. O nome foi estendido para o universo das terras privadas (ou tidas como tais), em que moradores tinham que realizar um pagamento ao proprietário, por utilizarem uma parcela delas. 
"peões". Não consegui traduzir os relatórios de pesquisa sobre as formas de imobilização da força de trabalho em um texto teórico. Essa experiência, entretanto, me serviu para trabalhar posteriormente alguns conceitos como "migração" e "uso comum" dos recursos. Quanto ao último, a releitura das entrevistas recuperava a memória do que havia observado diretamente, isto é, que havia diversas formas de uso comum dos recursos. Resgatei os dados sobre os campos naturais, onde o gado, de cada unidade familiar daquela primeira comunidade que pesquisei, era criado todo junto. Não havia cerca no campo. Mas havia uma família cujo chefe era designado como "vaqueiro", a quem cabia cuidar de todas as cabeças. E havia um sistema "de sorte": de quatro crias, ele ficava com uma. Com ele percorri os campos. Com o medidor de corda, percorri as áreas de agricultura. Com os outros que pescavam, fui para os córregos, que também eram de uso comum, observar como faziam as "tapagens".

Mas em momento algum atentei mais detidamente para os fatores identitários. Se autorrepresentavam como "foreiros", e assim os considerei, a partir do vínculo contratual, formal, verbal, com o proprietário, cuja unidade residencial era chamada de "sobrado", onde também se localizava a "venda" ou "quitanda". Ela se localizava em frente ao centro do povoado, que era de um formato semicircular. Nesta primeira experiência de campo, eu vivia em uma das casas, com uma das famílias. Dormia em um quarto, com três filhos do casal, em rede. Não havia água encanada nem banheiro, mas para tudo havia regras de uso. Fui aprendendo duramente essas coisas e vencendo minhas limitações.

\section{Lutas classificatórias, trabalho com os conceitos}

Essa experiência me levou à noção de uso comum, que articulava domínios comuns com privados. Não eram exatamente "comunais", como dizia a literatura histórica referente ao feudalismo; nem "comunitários", como faziam crer entidades confessionais; nem "coletivos", como pretendiam os que se viam como mais críticos; nem produto de uma ideologia "comunitarista", como liam os partidários do "comunitarismo" ou das chamadas "comunidades alternativas".

Me chamava atenção a combinação de domínios de uso familiar, privados, como a "roça", com aqueles de uso comum como a utilização aberta dos campos, águas, caminhos, florestas e do extrativismo em castanhais, babaçuais e açaizais "nativos". Verifiquei isto, com técnicas de observação direta, em quilombos e nas chamadas terras de santo, terras de preto e terras de índio. Constatei que existiam outras unidades de classificação, que não eram só aquelas referidas a "imóveis rurais”, que o INCRA [Instituto Nacional de Colonização e Reforma Agrária], a partir de 1972, colocaria no seu cadastro. Comecei a trabalhar com essas classificações não oficiais, construídas pelas próprias comunidades, hoje nomeadas como tradicionais.

A partir dessa experiência e do curso "Sociedades Camponesas", estreitei meus vínculos com os colegas, que estavam referidos ao Projeto Emprego e Mudança Socioeconômica no Nordeste (Palmeira et al. 1976). Em 1975, fui chamado para 
participar deste projeto. Fiquei com esse tópico referido à Amazônia e incumbido de pesquisar a região do semiárido. Trabalhei, inicialmente, com a Neide Esterci no sertão do Ceará, em Quixadá. Fizemos três trabalhos sobre unidades de produção familiar, um deles sobre as "terras soltas" (Almeida e Esterci 1977). O significado de uso comum, das terras de pretos e das terras de santos, conjuntamente às discussões de campo com Neide, me ajudou a entender o que denominavam de "terras soltas".

Percebi que havia distinções entre diferentes formas de uso: comum, comunitário, comunal, coletivo e comunitarista. Laís [Mourão] trabalhava com a noção de uso "comunal" da terra. Eu não apreciava as implicações históricas do termo “comunal”, embora o tenha utilizado, juntamente com Laís, em "Questões Agrárias no Maranhão Contemporâneo" (Almeida e Mourão 1976). Numa pesquisa posterior, em 1983/1984, estava com mais condições para fazer uma leitura crítica dele e a desenvolver distinções pelo uso, o que havia começado a fazer com as terras de santo, terras de índio, terras de preto, terras soltas, terras de ausentes e terras de parentes (Almeida 2008 [1989]).

Felizmente não fui tentado a aplicar nenhum modelo. Quando produzi o primeiro texto, fui bastante criticado pelos meus colegas. Disseram: "Essa situação de uso comum é de comunalidade, é dos Andes, isso não é daqui do Brasil”. Ao que respondi: "Gente, mas eu estou encontrando isso nos lugares em que realizo observações de campo. Será que eu é que fico projetando e querendo identificar isso?". Hoje já se mostra mais forte o sentimento crítico, e a aceitação destas categorias na estrutura agrária tornou-se uma realidade. Mas eu fiquei algum tempo preocupado de estar projetando as minhas preocupações teóricas sobre aquilo que eu observava empiricamente.

Continuavam trabalhando com "campesinato parcelar" e com unidades de trabalho familiar referidas a apenas um imóvel rural, que era aquele detido formalmente como "propriedade" pelo grupo familiar. Observei, entretanto, que, no caso dos babaçuais, se um coco caía da palmeira, todos podiam pegar. Na castanha também, o ouriço cai e qualquer família pode pegar. As famílias agrupam o que foi coletado num "monte". E ninguém pode pegar no "monte". É a ideia de que o trabalho seria definido quando se separa um elemento do outro. Quando você separa o peixe da água, você realiza trabalho. Quando você separa a amêndoa do coco e a castanha do ouriço, você realiza trabalho. Já a divisão do produto da "roça" vinha a partir do trabalho familiar nas casas de forno, não vinha de uma definição prévia de que pertencia a toda a comunidade. Não era coletivo.

Assim, trabalhar um conceito consiste em examinar todas as possibilidades que essa abordagem teórica tem para ser inteligível face a realidades localizadas. Nos cursos de história da ciência com o Castro Faria e com o Moacir Palmeira, aprendi que os conceitos não são apenas palavras. Se aproximam do modo como organizamos o sistema de pensamento. No texto "A Invenção da Migração" (Palmeira e Almeida 1977), eu não tinha nenhuma condição teórica de montar aquele esquema explicativo. A ordem de exposição foi de autoria do Moacir Palmeira. Eu tentei entendê-la e a executei. Redigi. As pessoas acharam "excelente", mas 
não tinha nada propriamente meu, no sentido de criatividade teórica. Era um produto do que eu entendi daquela discussão ou do que me foi explicado. Ora, como trabalhar com a invenção de um conceito como migração, que é supercomplexo, que é autoevidente, que prescinde de definição como quer o senso comum erudito? Como romper com essa linguagem metafórica, essa ideia de êxodo, que vem de metáforas bíblicas, que produzem sentidos figurados? Trabalhamos com o pressuposto de que sempre que se fala de migração, torna-se necessário definir de maneira explícita seu significado, porque todo mundo já supõe que sabe qual é. O procedimento de chamar o agente social de "migrante" consiste num equívoco derivado da força desta autoevidência, sobretudo porque o agente tem outra representação de si mesmo, possui uma identidade que o faz resistir a como é classificado pelo Estado, como se fosse um outsider. Tais implicações têm efeitos sobre a lógica formal do trabalho etnográfico. A briga que travei neste campo teórico confrontando a "naturalização" da descrição etnográfica encontra-se registrada em "Antropologia dos Archivos da Amazonia" (2008) e mais enfaticamente no "Nova Cartografia Social: territorialidades específicas e politização da consciência das fronteiras" (2013b).

Igor Rolemberg: Sobre desafios epistemológicos, o senhor comentou, em outra entrevista (Aragão e Oliveira 2019 [2012]), que eles estão presentes na criação de mapas, esse dispositivo sociotécnico, que, sabidamente, tem sido um importante instrumento de ação estatal. Poderia explicar novamente a particularidade dos mapas produzidos no Projeto Nova Cartografia Social da Amazônia (PNCSA)? Quais desafios permaneceram ao longo do tempo para atingirem seus objetivos?

AWBA: Ao trabalharmos com a noção de "nova cartografia social" como uma descrição específica, fundada na análise concreta de uma situação concreta, privilegiamos os fatores identitários como indissociáveis das demandas econômicas e dos problemas da vida cotidiana das unidades sociais mapeadas. Atentamos, sobretudo, para a dinâmica das relações sociais e dos usos dos recursos naturais. Produzimos mapas situacionais que consistiam em resultados disto. Menciono o exemplo [do quilombo] de Jamari, na região de Turiaçu (MA). Na primeira vez que a equipe do Projeto Vida de Negro aí esteve, os membros da comunidade se referiam a uma área de 8 mil hectares. Numa segunda vez, informavam 13 mil e houve variações posteriores. Não se tratava de informações não fidedignas. Não! Porque a ideia do território está ligada à quantidade de força que a unidade social detém em diferentes momentos face a seus antagonistas históricos, a cada vez que o grupo é levado a refletir sobre o que seria a sua territorialidade. Os mapas que produzimos são situacionais porque dialogam com estas variações. A demarcação pode ser uma forma de aprisionamento, mesmo que entendida, numa perspectiva gradualista, como uma etapa. Pode-se pensar que estas fronteiras eram porosas, as pessoas se deslocavam livremente por elas, e agora se veem obrigadas a cercar, a pensar em construir um muro, a fazer uma cancela de entrada e a ter um controle constante dos limites. Os processos de patrimonialização se mostram consoantes às modalidades de desenvolvimento do capitalismo, e a lógica neoliberal imagina que, pelo reconhecimento da propriedade, tudo se torna passível 
de comercialização.

Nesta ordem, no PNCSA nós não somos fazedores de mapas, nós criamos condições para que os grupos locais possam produzir seus próprios mapas, contemplando a possibilidade de variações, e só inserindo no mapa o que é relevante para eles. Nós estamos executando agora um projeto de instalação de minilaboratórios em unidades públicas de ensino superior do interior da Amazônia, que propiciam montar os mapas com softwares tecnologicamente avançados. Como são muitíssimos os alunos de famílias quilombolas, ribeirinhas e indígenas, que exercem práticas extrativas e protegem as florestas, supomos que estamos facultando condições de mapeamento às próprias comunidades e povos tradicionais. Há indígenas e quilombolas que concluíram mestrado e doutorado no âmbito do projeto.

\section{"Nova cartografia" como negação do mapeamento participativo e intera- tivo}

A Nova Cartografia Social não consiste num "mapeamento participativo", porque não cria um lugar social para as pessoas participarem. Aliás, "mapeamento participativo" é uma das expressões da retórica do Banco Mundial, do BID [Banco Interamericano de Desenvolvimento] e de agências ditas de desenvolvimento para implementar projetos que financiam. Concerne ao lugar que instituíram para os representantes das comunidades atingidas pelos projetos participarem ou se expressarem. O nosso projeto neste sentido não é participativo.

O significado de "nova cartografia social" se distingue também da expressão "cartografia social", como consta dos textos editados por empresas e agências de desenvolvimento. Elas se apropriaram dessa expressão pelos resultados que apresentou no âmbito dos movimentos e associações comunitárias, e a utilizam para fins de licenciamento ambiental. A "cartografia social", assim entendida, é um produto de empresas de consultoria e georreferenciamento para facilitar a aprovação de projetos. Elas ditam quem deve mapear, quando, onde e como. Nós elaboramos uma crítica sobre isso, que se chama "Consulta e Participação" (Almeida, Dourado, Lopes e Silva 2013).

O PNCSA também não é "interativo", como na proposta do Google, que mapeou favelas no Rio de Janeiro, mas está sendo processado por associações locais porquanto teria monopolizado o repertório de dados. Tampouco se trata de um "mapeamento colaborativo", como adotado pelas chamadas "grandes ambientalistas", que prestam serviços a governo, empresas e associações comunitárias, detendo o monopólio das informações coletadas. O objetivo delas é transformar o mapeamento em um "trabalho comunitário" e de "colaboração", uma medida oficial, ajustando a retórica mutualista às políticas governamentais.

A "nova cartografia social” propicia meios para uma descrição aberta e plural que reforça a etnografia ao produzir uma "nova descrição" em que os agentes sociais das unidades mapeadas são os artífices do mapeamento e a posição dos pesquisadores acadêmicos cinge-se à criação de condições de possibilidade para isto. Esta maneira de descrever permite resgatar a autoridade da antropologia, 
apoiada na precisão das informações, em dados fidedignos e georreferenciados, num trabalho de campo prolongado e crítico aos chamados "diagnósticos ligeiros", e num conjunto de relações de pesquisa fundado em confiabilidade mútua. Isto quando o conhecimento antropológico está sendo duramente questionado. Assim, os agentes sociais que a comunidade indicou para comporem a sua equipe definem quando e como os pesquisadores acadêmicos irão exercer sua ação de treinamento dessa equipe na captação de pontos e no uso de softwares. Só trabalhamos junto a povos e comunidades que nos enviaram convites para tanto. Recusamos o protagonismo de ditar o que deve constar nos mapas produzidos. Em articulação com este procedimento, pesquisadores do PNCSA exercem atividades pedagógicas regulares em programas de pós-graduação tanto no Maranhão e no Amazonas quanto no Pará, em Pernambuco, no Piauí, em Minas Gerais e na Bahia, formando indígenas, quilombolas, quebradeiras de coco babaçu, pescadores, ribeirinhos e demais membros de comunidades tradicionais.

RL: O que antropólogas e antropólogos precisam saber manejar em termos de saberes e técnicas para trabalharem com áreas e populações em conflito? Como compararia a sua experiência inicial de trabalho de campo com a dos pesquisadores que orienta e com quem trabalha hoje?

AWBA: Uma diferença é central. Quando nós chegamos ao Maranhão, em 1972, por exemplo, eu nos via como numa ação de características colonizadoras, mesmo que estivéssemos criticando a ação colonialista de ordens religiosas. Às vezes me perguntavam se eu fazia parte da família dos "proprietários" ou se era militar ou funcionário do governo. Me viam numa relação assimétrica e como o “outro". E a própria noção de antropologia que nos era transmitida ou mesmo os antropólogos que líamos - Berreman (1975) e [Clifford] Geertz (1959) - possuíam guias para os conduzirem no campo. Uma das posturas que adotamos desde o início foi que deveríamos consultar os mapas disponíveis e estudar a área antes de viajar. A presença de um guia fixo, remunerado, não constava de nosso planejamento do trabalho de campo, bem como não constava um "mateiro". A assimetria, todavia, sempre se mostrava evidente, escancarada. Éramos vistos como "brancos" ou, segundo uma percepção religiosa, como aqueles que estavam ali com uma visão apiedada e de suposta igualdade. Morávamos com eles, vivíamos o seu cotidiano, comíamos com eles, bebíamos com eles, os acompanhávamos nas áreas de cultivo, em festas, em rituais religiosos, mas não superávamos o fosso da assimetria radical.

$\mathrm{Eu}$, mesmo vindo do interior, porque sou da primeira geração urbana da minha família, acostumado a andar descalço, tinha algumas coisas de aparente aproximação. Mas não vencia essas barreiras. Não me detinha em observações intimistas com as pessoas do povoado, por princípio. Na equipe tínhamos diferentes visões sobre o que fazer. Eu achava que era uma postura ética, mas isto não se sustentou no tempo. O professor [Roque] Laraia (1993) resume, sem problematizar, este "código de ética" dos antropólogos, quando do início de suas atividades (Almeida 2018).

Nas últimas três décadas e meia, com o advento de formas político-organi- 
zativas que levam em conta o fator identitário, uma consciência ambiental aguda e raízes locais profundas, as relações de pesquisadores com unidades sociais designadas como tradicionais sofreram mudanças radicais. Além disto, o acesso de membros destas unidades sociais ao sistema de ensino descortinou novas possibilidades de relações de pesquisa. Acrescente-se o fato de passarmos a ser convidados para contribuir na produção de conhecimentos cartográficos relativos a tais comunidades e povos. Recorde-se ainda que o processo de produção cartográfica destas comunidades, que tem como marco os materiais da denominada “Guerra dos Mapas" está completando 31 anos (Almeida 1995). Nosso acesso às comunidades não é visto sob nenhum estranhamento maior; ao contrário, diversos obstáculos desta natureza estão sendo superados.

No âmbito da "nova cartografia social", tudo isto tem nos mantido numa posição bastante secundária, mas com uma profundidade crescente nos trabalhos de pesquisa, facilitando nossa recusa de sermos os principais mediadores ou protagonistas. Os efeitos disso são surpreendentes. Por exemplo, para além de quaisquer previsões houve a titulação definitiva da comunidade quilombola Ilha de São Vicente (TO), neste atual governo. Em plena pandemia neste início de 2021, a Aldeia Beija-Flor, em Rio Preto da Eva (AM), foi vitoriosa na ação jurídica em que demandava indenização. Mapeamos de uma maneira aparentemente neutralizante, mas as vitórias são concretas. Há os que criticam, mas estamos conseguindo defender os interesses das comunidades e povos tradicionais. $\mathrm{O}$ maior quilombo do Brasil, em extensão, foi titulado a partir do trabalho de um pesquisador do

PNCSA. Trata-se da comunidade quilombola de Cachoeira Porteira, com $228 \mathrm{mil}$ hectares. O processo de legitimação do PNCSA está consoante à situacionalidade dos mapas e de sua recepção positiva em termos técnicos. A situacionalidade não é só do território, mas do seu uso e do seu reconhecimento efetivo, que alcança o povo ou a comunidade.

Antes, a relação de assimetria mencionada era um fato dado, porque não havia elemento identitário em jogo, com força relativizadora. A assimetria persiste, mas pelas situações de reconhecimento pode-se relativizá-la e, no plano do trabalho científico, tratá-la rigorosamente com o discernimento da análise reflexiva. A despeito dos senões pós-modernistas, está-se diante da consolidação de um processo de produção intelectual em que toda ciência é reflexiva.

No momento atual, os PPG's registram muitíssimos discentes indígenas e quilombolas, o que tem efeitos consideráveis sobre o conjunto da produção acadêmica. No curso de pós-graduação em antropologia da UEMA, em que são efetivadas práticas relativas à nova cartografia social, a maior parte dos alunos é indígena e quilombola. O curso encontra-se na oitava turma e os que defenderam as dissertações já estão habilitados para serem professores.

[Bronislaw] Malinowski (2018 [1922]) queria construir uma antropologia do ponto de vista do nativo. Sol Tax (2020 [1958]) retrucou: "Nós vamos construir uma antropologia não do ponto de vista do nativo, mas a serviço do nativo". Seria a antropologia da ação. Já [George] Foster (1964 [1962]) arrematou: "Nada disto! Vamos construir uma antropologia at work, uma antropologia em ação, do de- 
senvolvimento, objetivando o progresso material das comunidades tradicionais". Esta antropologia aplicada pode abranger iniciativas como arranjar um reprodutor Nelore capacitado ou o banheiro mais apropriado para uma unidade camponesa. Temos aqui pelo menos três visões: Malinowski, Sol Tax e Foster (Almeida 2020). Imagine uma quarta visão, que vise incorporar reflexividade ao argumento de Sol Tax, como sublinhava Roberto Cardoso [de Oliveira]. Ou uma quinta visão que discuta as proposições recentes da antropologia, quando os próprios membros das comunidades estudadas estão se tornando antropólogos e produzindo elementos para uma descrição etnográfica. Este processo, designado como anticolonialista, parece já ganhar corpo no Equador, na Bolívia e no Chile (Zapata 2017).

Hoje, no Brasil, há centenas de identidades coletivas objetivadas em movimentos sociais, cujas lutas não podem ser menosprezadas numa análise política, porque constituem o coração da cena política, mais proeminentes até, em determinados regiões, do que os partidos. Há redefinições dos significados de política, novas maneiras de fazer política e de conceber as formas de organização política (Almeida 2011). As oposições entre "classe" e "identidade”, "partido" e "movimento" ou "fragmentação" e "centralidade" se mostram despolitizadas e artificiais numa situação em que há processos de lutas concretos. Os acontecimentos de junho de 2013, no Brasil, surpreenderam os que insistiam naquelas oposições e em esquemas explicativos defasados. Está difícil de se descobrirem vias de interlocução com essas novas formas político-organizativas, que conjugam reivindicações econômicas com lutas identitárias, lutas pela terra com mobilizações por direitos territoriais. Provavelmente esse é o desafio maior a ser discernido pelos antropólogos.

IR: Professor, nos primeiros anos após a redemocratização, o senhor publicou "O Intransitivo da Transição", segundo capítulo de sua tese, que trata do que restou de entulho autoritário a impedir uma transformação mais profunda na estrutura fundiária brasileira, de modo a torná-la mais aberta a novas formas de acesso, ocupação e uso da terra, nos diferentes biomas. Ali está presente uma revisão minuciosa de dispositivos normativos que dão amparo legal ao chamado padrão concentracionista da terra. Fazendo uma atualização do diagnóstico, que dispositivos, nas legislações agrária e ambiental de hoje, promovem essa tendência concentracionista?

AWBA: Bom, hoje o Senado está discutindo o Projeto de Lei (PL) n ${ }^{\circ}$ 510/2021. Há uma audiência pública para debater esse PL que visa ampliar as possibilidades de regularização fundiária em terras da União. Os bispos da Amazônia e a Coalizão Brasil Clima Florestas e Agricultura lançaram cartas contra esse PL. As federações de trabalhadores rurais, a CONTAG [Confederação Nacional dos Trabalhadores Rurais Agricultores e Agricultoras Familiares] e as entidades confessionais estão se mobilizando contra esse PL. Atualmente é permitida a regulação fundiária de terras da União, ocupadas antes de 22 de julho de 2008. A proposta de agora é passar este marco temporal para 2019 e com áreas de até 2.500 hectares. Isso pode ser um reconhecimento em massa de grilagem. E é defendido pela CNA [Confederação da Agricultura e Pecuária do Brasil] e pela Frente Parlamentar da 
Agropecuária, a chamada bancada ruralista. Eles estão enfraquecendo a questão ambiental e flexibilizando os requisitos para regulação fundiária a fim de facilitar a grilagem. Esquecem que pela Lei $\mathrm{n}^{\circ} 11.592 / 2009$ quase 200 mil posseiros, entre pequenos e médios produtores rurais, poderiam receber título de propriedade, segundo a $\mathrm{CONTAG}^{3}$. Está-se frente a uma medida ágil de legalização da ocupação das terras da União. Este dispositivo permitirá que florestas públicas invadidas, já desmatadas, sejam legalizadas.

Nós percebemos que os que defendem acabar com desmatamento, são os que favorecem o desmatamento. Essa ideia da retórica diferindo da prática é impressionante. São os mesmos que estão na grilagem de terras públicas, flexibilizando licenciamento ambiental, responsáveis por um terço do desmatamento e que têm uma tentativa de denúncia da Convenção $169^{4}$. Estamos enfrentando uma ofensiva muito grande desses interesses do agronegócio. Eram mais comedidos, agora estão no enfrentamento, de forma ofensiva.

Acho que o primeiro ato ofensivo diz respeito àquele dia do fogo de agosto de 2019, no início da estação seca de verão na Amazônia. Nós percebemos ali uma coalizão de interesses que até então não havia se manifestado dessa forma. Foi a primeira vez que vi empresas mineradoras, que trabalham com ouro primário, com escavação, e grupos de garimpeiros que trabalham com ouro aluvial, superficial, somarem forças, no Tapajós. Mais agropecuaristas da beira da BR-163, mais comerciantes de Trairão e outros povoados e municípios nas bordas da BR-163. Foi a primeira vez que eu vi essa coalizão de interesses funcionando. E essa coalizão criou o dia do fogo. Fez um ensaio de medição de forças face à ação governamental. Isso é paralelo ao rio Jamanxim, ao rio Tapajós, com garimpos e áreas dos Munduruku, áreas de proteção ambiental e do exército. Então achei que aquilo era um balão de ensaio para outras ações. Isso está no nosso livro sobre mineração, no artigo da Ítala Nepomuceno, que mora em Itaituba (Almeida, Melo, Nepomuceno, e Benvegnú 2019). Esses desmatamentos todos estão ligados a essa lógica da regularização fundiária. "Olha, é uma terra pública antiga, nós já desmatamos, ocupamos, queimamos, e agora nós queremos titular nosso nome”. Eles fizeram isso em larga escala, articulados com essas forças do legislativo. E agora mudam a data, de 27 de julho de 2008, para 10 de dezembro de 2019; quer dizer, o dia do fogo está dentro do que planejaram.

Alterar o marco temporal da regularização fundiária de terras públicas da União, flexibilizar licenciamento ambiental, tentativa de denúncia da Convenção 169/OIT [Organização Internacional do Trabalho]. Estas técnicas expressam o modus operandi da vertente autoritária do desenvolvimento capitalista.

RL: Houve mudança em termos do que o senhor e outros pesquisadores chamaram de "processo de devastação" (Almeida, Shiraishi Neto e Martins, 2005), em diálogo com o conceito de "processo de ambientalização" de José Sérgio Leite Lopes et al. (2004)?

AWBA: Antes, falar de regularização fundiária já era uma forma de negar a reforma agrária. Atualmente, o fator ambiental, através dos seus agentes, passou a incorporar o fator fundiário e a ter novos candidatos a especialistas. A expressão
3 O PL 510/2021 altera a Lei $n^{\circ} 11.952 / 2009$, que permitia a privatização, sem licitação, de áreas públicas com até 1.500 hectares ocupadas antes de dezembro de 2004 (Almeida 2012). Sobre o PL 510, ver: https://bit.ly/3w5fwy6. Acesso em 15 maio 2021.

4 "Denúncia" aqui se reveste de um significado jurídico específico: trata-se da "denúncia de tratado internacional", quando um país resolve unilateralmente deixar de ser parte no acordo. 
"regularização fundiária” voltou a prevalecer. Associações voluntárias do terceiro setor começaram a fazer trabalhos articulados com a lógica de empreendimentos dos agronegócios. A questão ambiental começou a ser uma questão de muita abrangência e comporta profundas contradições. O antropólogo José Sérgio [Leite Lopes] chamou atenção para um processo de ambientalização e de como isso se expande para todos os domínios da vida social. Agências ambientalistas, numa visão protagonística de si mesmas, passaram a se ver como novos especialistas em problemas agrários e fundiários. Passaram a falar com autoridade em vários domínios de conhecimento da estrutura agrária sobre os quais não detêm os critérios de competência de saber específicos. Construíram um saber ancorado em técnicas de leitura de imagens de satélite em detrimento do trabalho de campo e de um conhecimento produzido a partir de realidades localizadas.

Nosso trabalho de mapeamento social é radicalmente diferente. Combinamos mapas, minilaboratórios, museus e a formação de membros das próprias comunidades na arte de mapear. Montamos mais de 15 pequenos museus, chamados Centros de Ciências e Saberes, dentro dos povoados, que focalizam a memória daquela unidade social (comunidade, povo, grupo, tribo). Montamos inúmeros minilabs na Amazônia, que consistem em poucos equipamentos, de baixo custo. Permitem treinar membros das comunidades tradicionais, são autônomos. Esses minilabs teriam condição de registrar, em tempo real, os desmatamentos e intrusamentos. Localizados próximos ou dentro de aldeias, em povoados, na fronteira dos territórios, ou nas bordas das comunidades, teriam condição de, em tempo real, dizer o que de fato estaria ocorrendo. Esta inserção localizada faculta compreensões acuradas e discernimentos não legíveis numa imagem de satélite que propicia uma visão genérica. Imaginem a dificuldade de distinguir o verde de diferentes palmáceas. Na Amazônia há centenas de palmáceas e a sua distinção é imprescindível para entender dada região ou economia.

O processo de devastação não é uma mera supressão da cobertura vegetal, como usualmente definem. A neutralização desse processo implica construir uma alternativa. Esses mapas que ajudamos a produzir levam um ano e meio para serem elaborados. Há sucessivas oficinas de mapas. Esse processo de produção cartográfica neutraliza outros processos que são céleres, ágeis, e que têm efeitos muito sentidos pelas comunidades.

Este é um momento em que a legislações agrária e ambientalista estão sendo apreciadas na Comissão de Meio Ambiente do Senado, para discutir a situação da regularização fundiária em terras devolutas, em terras da União. A Comissão de Meio Ambiente passará a ter papel de destaque na legislação agrária?

IR: Sobre a nova ofensiva do agronegócio, em relação às elites agrárias, o senhor cunhou o termo das agroestratégias para nomear o conjunto de ações dos agronegócios, que atacam direitos étnicos e territoriais para ampliar o estoque fundiário sob sua possessão, num contexto internacional de "corrida por terras", de elevação de seu valor como ativo e de apreciação monetária das ditas commodities (Almeida 2010). Estudos sobre elites agrárias mostram que há forças centrífugas e centrípetas que dificultam ou facilitam a concertação do "agrone- 
gócio" (Pompeia, 2021). Como esse fenômeno pode ser apreendido? Com quais ferramentas?

AWBA: Acho que o melhor exemplo com o qual trabalhamos foi o dos megaprojetos. É onde as agroestratégias se revelam com a maior transparência. Tem-se uma elevação geral dos preços das commodities e intensificação da ação dos interesses, inclusive cercado de um certo triunfalismo: "Tudo é pop, tudo é agro". Argumentam sob uma aura de racionalidade neoliberal, de avanço tecnológico, e uma aura de futuro, de progresso. Para mim, esses empreendimentos constituem as novas plantations. Essas agroestratégias têm a mesma lógica de economias agroexportadoras com monoculturas voltadas para o mercado externo. Utilizam força de trabalho imobilizada. As denúncias de trabalho escravo são recorrentes nestes empreendimentos. Usam grandes extensões de terra, concentrando-a. Estão numa expansão cada vez maior. Essas características são aproximáveis do sistema de plantation. Os interesses que os representam encontram-se na Frente Parlamentar da Agropecuária e na CNA, estão na Comissão de Meio Ambiente. Começam a se estruturar enquanto organismos militantes. Por que eles têm que se mobilizar? Porque a dominação no campo já não é mais naturalizada. Não estamos mais numa situação colonial, mas seus instrumentos acionam mecanismos colonialistas.

Se isso for verdadeiro, os seus efeitos são conhecidos. Quando o preço das commodities descender, sabe-se o que poderá acontecer. Já assistimos isto com o café e o algodão, vivemos isso com a cana-de-açúcar, tanto que o [Eric] Hobsbawn cita que as plantations da costa nordestina estão em derrocada desde o século XVIII. As chamadas elites agrárias, em São Paulo, transferiram seus recursos para a industrialização. No caso brasileiro, as elites rurais tornaram-se elites industriais. Os recursos do café foram investidos em indústrias paulistas. Os recursos do algodão foram investidos em indústrias têxteis do Maranhão. Trata-se de um processo historicamente diferente da França, por exemplo, onde a burguesia industrial surge depois que a aristocracia agrária é passada na guilhotina. Também é diferente da Inglaterra, onde os industriais emergem depois que reformas neutralizam o poder dos grandes proprietários rurais. É ainda diferente dos Estados Unidos, em que ocorre uma "Guerra Civil”, de Secessão, para destruir a força do sistema de plantations e destruir uma elite agrária a ele vinculada. Emerge aí uma elite industrial e financeira. O fundamento do capitalismo autoritário seria este (Velho 2009 [1976]). Daí porque não temos transformações profundas na estrutura agrária e o Brasil possui os mais elevados índices de concentração fundiária.

Temos que estar atentos para estratégias de grandes agências ambientalistas, que querem fazer uma aliança com esses interesses que sustentam as "novas plantations". É imenso o risco de acelerar uma destruição. Estes interesses estão em marcha, como estamos vendo nessa audiência pública sobre o PL 510/2021 na Comissão do Meio Ambiente.

As agroestratégias trazem um elemento central da lógica do sistema de plantation: os empreendimentos têm que estar em expansão permanentemente e incorporar novas terras. Por que se percebe um gradativo abandono de "velhas" áreas 
de plantation, se consideram os empreendimentos dos agronegócios tão avançados tecnologicamente? As agroestratégias ilustram isto, incorporar novas áreas para obter resultados melhores em menos tempo. Há uma tendência ascensional dos preços de commodities que propicia isto. Mas os preços são voláteis. É de grande risco. As políticas neoliberais alimentam riscos crescentes.

Em relação às mineradoras, sabem quantas barragens de rejeitos estão para serem rompidas? 695 barragens de rejeitos ameaçadas. A questão ambiental se tornou uma questão de risco controlado. Há uma financeirização em curso. As empresas tornaram os problemas ambientais mantidos sob seguro, por grandes seguradoras, numa conjuntura de elevação geral do preço das commodities minerais. Por exemplo: na tragédia de Mariana, quem arcou com os danos? A mineradora Samarco? Não. A empresa de seguro Allianz teria pagado o valor do seguro.

Seja na África ou na Ásia, constata-se uma financeirização não apenas da questão ambiental, mas dos grandes empreendimentos dos agronegócios. O seguro das catástrofes ditas "naturais" - rompimento de barragens de rejeitos, queimadas de grandes áreas, acidentes com barcaças de transporte de dendê, descarrilhamento de trens de minério - encontra um mercado em plena expansão. Em suma, as agroestratégias passaram a terceirizar riscos. Temos uma nova coalizão de interesses. Grandes fundos estão investindo no setor imobiliário, aquisição de terras agriculturáveis e em empresas alimentícias. O principal dono de terras agriculturáveis dos Estados Unidos é Bill Gates. Quanto à alimentação, parecem estar buscando maior interlocução com certos princípios da chamada "segurança alimentar", assegurando, todavia, uma expansão dos agronegócios.

RL: O senhor e outros pesquisadores do PNCSA organizaram o livro Pandemia e Território (Almeida, Acevedo Marin, e Melo 2020). Como a pandemia tem agravado essas ameaças proporcionadas pelas agroestratégias e como a Nova Cartografia tem lidado com esse cenário?

AWBA: Entramos nesse trabalho de uma forma meio autodefensiva. Começamos a perceber que os efeitos da peste estavam atingindo muito profundamente os movimentos. Percebemos perdas não apenas de lideranças, mas de pessoas que detinham a memória de episódios trágicos e de chacinas, como a dos Waimiri-Atroari, que ainda estão por serem esclarecidos. A pandemia não atinge a todos por igual. Quando atinge uma antiga liderança indígena ou quilombola, afeta a memória de um povo inteiro.

Por isso, começamos a registrar óbitos de quilombolas e indígenas. Mas tivemos dificuldades. Famílias conhecidas se recusavam, porque muitos contraíram em cultos e não queriam falar disto. A pandemia não é uma doença ocupacional, quem morre não tem direito a nada. Começamos a travar essa discussão afirmando o sentido das indenizações com as famílias. Para fazer isso, achei que devíamos elaborar um grande livro de registros.

Elaboramos uma noção de obituário, no sentido contrário da ilusão biográfica. Nós elencamos mais de uma centena e meia de textos, que colocamos nessa página do obituário e fizemos cartazes com fotos. Começamos a agrupar os retratos porque achamos que era necessário mostrar qual era o povo, qual era a etnia, qual 
era a pessoa. Não entrar no genérico: "morreram 20 índios, 30 índios”. Nada disso. É o que acho que pode ser feito agora na chacina do Jacarezinho ${ }^{5}$. Situar e constituir o exame de corpo delito por via da etnografia de documentos. Nós fizemos isso com o "Pandemia e Território". Foi uma técnica da etnografia de documentos, provocar uma interlocução virtual e produzir uma descrição a partir daí.

Então, esse trabalho mostrou para nós as inconsistências que estão vindo à tona com as mais de 430 mil mortes. Naquele momento nós não tínhamos 50 mil mortes. E já havíamos intuído para onde poderíamos ir. Atos genocidas naturalizados e expostos como problemas burocráticos.
5 A chacina na favela Jacarezinho ocorreu no Rio de Janeiro em maio de 2021.28 pessoas foram mortas. Ver: https://bit. ly/3ovKOH7. Acesso em 15 maio 2021. 


\section{Referências}

Almeida, Alfredo Wagner Berno de. 1977. "Uma genealogia de Euclides da Cunha”. In Arte e sociedade: ensaios de sociologia da arte, org. Gilberto Velho, 88-129. Rio de Janeiro: Zahar.

Almeida, Alfredo Wagner Berno de. 1979. Jorge Amado, política e literatura: um estudo sobre a trajetória intelectual de Jorge Amado. Rio de Janeiro: Campus.

Almeida, Alfredo Wagner Berno de. 1991. "O intransitivo da transição: o Estado, os conflitos agrários e a violência na Amazônia (1985-1989)". In Amazônia: a fronteira agrícola 20 anos depois, org. Philippe Léna e Adélia Engrácia de Oliveira, 259-90. Belém: Museu Paraense Emílio Goeldi.

Almeida, Alfredo Wagner Berno de. 1993. "Conflito e mediação: os antagonismos sociais na Amazônia segundo os movimentos camponeses, as instituições religiosas e o Estado". Tese de Doutorado, Universidade Federal do Rio de Janeiro.

Almeida, Alfredo Wagner Berno de. 1995. Carajás: a guerra dos mapas. Belém: Supercores.

Almeida, Alfredo Wagner Berno de. 2008 [1989]. "Terras de preto, terras de santo, terras de índio - uso comum e conflito". In Terra de quilombo, terras indígenas, "babaçuais livre", "castanhais do povo", faixinais e fundos de pasto: terras tradicionalmente ocupadas, org. Alfredo Wagner Berno de Almeida. $2^{\text {a }}$ ed. Manaus: PGSCA; UFAM.

Almeida, Alfredo Wagner Berno de. 2008. Antropologia dos Archivos da Amazônia. Rio de Janeiro: Casa 8; Fundação Universidade do Amazonas.

Almeida, Alfredo Wagner Berno de. 2010. “Agroestratégias e desterritorialização - direitos territoriais e étnicos na mira dos estrategistas dos agronegócios". In Capitalismo globalizado e recursos territoriais: Fronteiras da acumulação no Brasil contemporâneo, org. Alfredo Wagner Berno de Almeida et al., 101-43. Rio de Janeiro: Lamparina.

Almeida, Alfredo Wagner Berno de. 2012. "Territórios e territorialidades específicas na Amazônia: entre a 'proteção' e o ‘protecionismo'”. Caderno CRH 25(64): 63-71.

Almeida, Alfredo Wagner Berno de. 2013a. "A turma do Brasil Central” e a "Antropologia da Amazônia". Apresentação. In Frentes de Expansão e Estrutura Agrária - Estudo do Processo de Penetração numa Área da Transamazônica, org. Otávio G. Velho. $3^{\mathrm{a}}$ ed. Manaus: UEA.

Almeida, Alfredo Wagner Berno de. 2013b. "Nova cartografia social: territorialidades específicas e politização da consciência das fronteiras". In Povos e comunidades tradicionais, org. Alfredo Wagner Berno de Almeida, Emmanuel de Almeida Farias Jr., 157-73. Manaus: UEA.

Almeida, Alfredo Wagner Berno de. 2014 [1993]. "Aggiornamento Agônico: A trajetória das instituições religiosas como mediadoras dos conflitos agrários na Amazônia". In Mobilização social na Amazônia: a “luta' por justiça e por educação, org. Paula Lacerda (org.), 69-108. Rio de Janeiro: E-Papers.

Almeida, Alfredo Wagner Berno de. 2018. “'Cowboy anthropology': nos limites da autoridade etnográfica”. EntreRios 1: 8-35.

Almeida, Alfredo Wagner Berno de. 2020. “'Antropologia da ação' (Action anthropology) versus 'Antropologia em ação' (Anthropology at work/Applied anthropology”. Guarimã Revista de Antropologia \& Política 1: 100-13. 
Renata Lacerda e Igor Rolemberg

Almeida, Alfredo Wagner Berno de, Rosa Elizabeth Acevedo Marin, e Eriki Aleixo de Melo. 2020. Pandemia e Território. São Luís: UEMA; PNCSA.

Almeida, Alfredo Wagner Berno de, Sheilla Borges Dourado, Danilo da Conceição Serejo Lopes, e Eduardo Faria Silva. 2013. Consulta e participação: a crítica à metáfora da teia de aranha. Manaus: UEA; UFAM.

Almeida, Alfredo Wagner Berno de, e Neide Esterci. 1977. "Terras soltas e o avanço das cercas”. In Projeto Emprego e Mudança Sócio-Econômica no Nordeste, org. Moacir Palmeira et al. v. 2. Rio de Janeiro: MN; UFRJ; IPEA.

Almeida, Alfredo Wagner Berno de; Eriki Aleixo de Melo, Ítala T. Rodrigues Nepomuceno, e Vinícius Cosmos Benvegnú, orgs. 2019. Mineração e Garimpo em Terras tradicionalmente ocupadas: conflitos sociais e mobilizações étnicas. Manaus: UEA Edições; PNCSA.

Almeida, Alfredo Wagner Berno de, e Laís Mourão. 1976. Questões agrárias no Maranhão contemporâneo. Pesquisa Antropológica 9(10): 1-27.

Almeida, Alfredo Wagner Berno de, Joaquim Shiraishi Neto, e Cynthia Carvalho Martins. 2005. Guerra Ecológica nos Babaçuais: o processo de devastação dos palmeirais, a elevação do preço de commodities e o aquecimento do mercado de terras na Amazônia. São Luís: Lithograf.

Aragão, Helena de Moura, e Lúcia Lippi Oliveira,. 2019. Entrevista Alfredo Wagner Berno de Almeida, depoimento realizado em 15 fev. 2012, 1h 47min. Rio de Janeiro: CPDOC/FGV. (Convênio Fundação Ford). Acesso em 10 maio 2021. Disponível em: http://www.fgv.br/cpdoc/historal/arq/Entrevista1973.pdf

Berreman, Gerald D. 1975. "Etnografia e controle de impressões em uma aldeia do Himalaia”. In Desvendando máscaras sociais, org. Alba Zaluar Guimarães, 123-74. Rio de Janeiro: Livraria Francisco Alves.

Bourdieu, Pierre. 2005. Esboço de auto-análise. São Paulo: Companhia das Letras

Canguilhem, Georges. 1990. Études d'histoire et de philosophie des sciences concernant les vivants et la vie. Paris: Vrin.

Canguilhem, Georges. 2000 [1977]. Idéologie et rationalité dans l'histoire des sciences de la vie. Paris: Librairie Philosophique J. Vrin.

Derrida, Jacques. 1991 [1972]. Margens da filosofia. Campinas: Papirus.

Dias, Guilherme Mansur. 2009. “Entrevista: Alfredo Wagner Berno de Almeida“. Ruris 3: 17-54.

Foster, George M. 1964 [1962]. As culturas tradicionais e o impacto da tecnologia. Rio de Janeiro: Fundo de Cultura.

Foucault, Michel. 2010 [1976]. História da Sexualidade 1: a vontade de saber. São Paulo: Graal.

Geertz, Clifford. 1959. "Form and Variation in Balinese Village Structure". American Anthropologist 61: 991-1012.

Laraia, Roque de Barros. 1993. Ética e Antropologia: algumas questões. Brasília: UnB. (Série Antropologia ${ }^{\circ}$ 157). Acesso em 15 maio 2021. Disponível em: http://dan.unb. br/images/doc/Serie157empdf.pdf.

Leite Lopes, José Sérgio et al., org. 2004. A ambientalização dos conflitos sociais: Participação e controle público da poluição industrial. Rio de Janeiro: Relume Dumará.

Lima, Widney P., João D. Ramos, e Cristhiano K. da Silva. 2013. “Entrevista com o pro- 
Renata Lacerda e Igor Rolemberg

fessor Alfredo Wagner Almeida". Espaço Ameríndio 7: 254-70.

Malinowski, Bronislaw. 2018 [1922]. Argonautas do Pacífico Ocidental. São Paulo: Ubu.

Mintz, Sidney W. 1985. "From Plantations to Peasantries in the Caribbean". In Caribbean Contours, org. Sidney W. W. Mintz e Sally Price, 127-53. Baltimore: The Johns Hopkins Press.

Palmeira, Moacir et al. 1976. Emprego e Mudança Sócio-Econômica no Nordeste. Anuário Antropológico 1: 201-42.

Palmeira, Moacir, e Alfredo Wagner Berno de Almeida. 1977. "A invenção da migração: relatório de pesquisa". In Projeto Emprego e Mudança Sócio-Econômica no Nordeste, org. Moacir Palmeira et al., v. 5. Rio de Janeiro: PPGAS/MN. Mimeografado.

Pinto, Louis. 2014. Sociologie et philosophie: libres échanges. Montreuil: Ithaque.

Pompeia, Caio. 2021. Formação política do agronegócio. São Paulo: Elefante.

Tax, Sol. 2020 [1958]. Antropologia da Ação. Guarimã Revista de Antropologia \& Política 1: 114-23.

Velho, Otávio. 2009 [1976]. Capitalismo Autoritário e Campesinato. Rio de Janeiro: Centro Edelstein de Pesquisas Sociais.

Wolf, Eric, e Sidney W. Mintz. 1957. "Haciendas and plantations in Middle America and the Antilles”. Social and Economic Studies 6(3): 380-412.

Zapata, Claudia. 2017. Los intelectuales indígenas en Ecuador, Bolivia y Chile. Diferencia, colonialismo y anticolonialismo. Santiago: LOM. 